\title{
Image Enhancement Techniques: A Selected Review
}

\author{
Nancy $^{1}$, Er. Sumandeep Kaur ${ }^{2}$ \\ I' Student, UCoE, Punjabi University, Patiala, India.) \\ ${ }_{2}^{2}$ (Assistant Professor, UCoE, Punjabi University, Patiala, India.)
}

\begin{abstract}
Image enhancement is one of the key issues in high quality pictures such as digital cameras. Since image clarity is very easily affected by lighting, weather, or equipment that has been used to capture the image. These conditions lead to image may suffer from loss of information. The main purpose of image enhancement is to bring out detail that is hidden in an image or to increase contrast in a low contrast image. It provides a multitude of choices for improving the visual quality of images. That's why it is used in a huge number of applications with important challenges such as noise reduction, degradations, blurring etc. This paper presents a literature review on some of the image Enhancement techniques for enhancing images like Contrast Stretching, Fuzzy grayscale enhancement, Fusion based approach on MSRCR, A hybrid algorithm for spatial and frequency domain etc. Comparison of all the techniques concludes the better approach for its future research.
\end{abstract}

Keywords: Digital Image Processing, Fuzzy grayscale enhancement, Image enhancement, MSE, PSNR, Retinex, Spatial And Frequency Domain.

\section{Introduction}

Image enhancement is to improve the interpretability or perception of information in images to provide better input for other automated image processing steps. The image acquired from natural environment with high dynamic range includes both dark and bright regions. Due to exceed in dynamic range of human eyes sensing, those image are difficult to perceive by human eyes. Image enhancement is a common approach to improve the quality of those images in terms of human visual perception. Enhancement techniques can be divided into two categories namely:

- Spatial domain methods

- Transform domain methods

Spatial domain technique enhances an image by directly dealing with the intensity value in an image. Large number of techniques have been focussed on the enhancement of gray level images in the spatial domain. These methods include histogram equalization, high pass filtering, low pass filtering, homomorphic filtering, etc. These methods have been also applied to color image enhancement in the R-G-B space.

Transform domain enhancement techniques involve transforming the image intensity data into a specific domain by using methods such as DFT, DCT, etc. and the image is enhanced by altering the frequency content of the image.

Our aim is to enhance the quality of the recorded image as to how a human being would have perceived the scene. This property that we aim to achieve is called 'color constancy. This property cannot be achieved using standard image enhancement techniques such as histogram equalization, contrast stretching etc. Image enhancement is applied in every field where images are ought to be understood and analyzed. For example, medical image analysis, analysis of images from satellites etc.
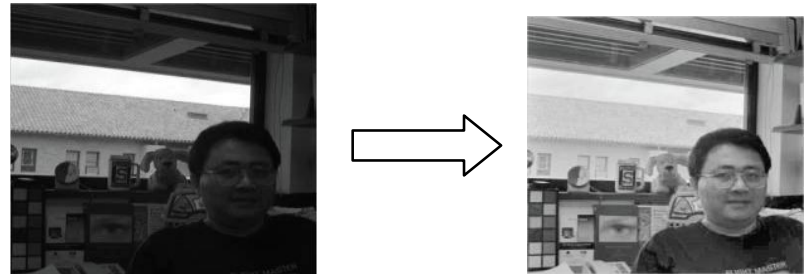

Fig.1: Showing the effect of Image Enhancement

\section{Literature Review}

In this section, we are presenting the research work of some prominent authors in the same field and explaining a short description of various techniques used for image enhancement.

A. Adin Ramirez Rivera, Byungyong Ryu, and Oksam Chae, "Content-Aware Dark Image Enhancement Through Channel Division", 2012[1] proposed a content-aware algorithm that enhances dark images, sharpens edges, reveals details in textured regions, and preserves the smoothness of flat regions. This algorithm produces 
an ad hoc transformation for each image, adapting the mapping functions to each image's characteristics to produce the maximum enhancement. They analyzed the contrast of the image in the boundary and textured regions, and group the information with common characteristics. These groups model the relations within the image, from which the transformation functions were extracted. The results were then adaptively mixed, by considering the human vision system characteristics, to boost the details in the image.

B. Deepak Ghimire and Joonwhoan Lee," Nonlinear Transfer Function-Based Local Approach for Color Image Enhancement,"2011[2] proposed a method in which the image enhancement was applied only on the V (luminance value) component of the HSV color image and $\mathrm{H}$ and S component were kept unchanged to prevent the degradation of color balance between HSV components. The V channel was enhanced in two steps. First the $\mathrm{V}$ component image was divided into smaller overlapping blocks and for each pixel inside the block the luminance enhancement was carried out using nonlinear transfer function. In the second step, each pixel was further enhanced for the adjustment of the image contrast depending upon the center pixel value and its neighborhood pixel values. Finally, original $\mathrm{H}$ and $\mathrm{S}$ component image and enhanced V component image were converted back to RGB image.

C. Sudharsan Parthasarathy, Praveen Sankaran," Fusion Based Multi Scale RETINEX with Color Restoration for Image Enhancement,"2012[3] proposed that a fusion based approach on Multi Scale Retinex with Color Restoration(MSRCR) would give better image enhancement. Lower dynamic range of a camera as compared to human visual system causes images taken to be extremely dependent on illuminant conditions. MSRCR algorithm enhances images taken under a wide range of nonlinear illumination conditions to the level that a user would have perceived it in real time. One of the enhancement techniques that tries to achieve color constancy is Retinex. In Multi Scale Retinex(MSR),they average multiple SSR(Single Scale Retinex) images to obtain a net improved image.

D. S. Bronte, L. M. Bergasa, P. F. Alcantarilla, "Fog Detection System Based on Computer Vision Techniques", [4] proposed a real-time fog detection system using an on-board low cost b\&w camera, for a driving application. This system was based on two clues: estimation of the visibility distance, which was calculated from the camera projection equations and the blurring due to the fog. Because of the water particles floating in the air, sky light gets diffuse and, focus on the road zone, which is one of the darkest zones on the image. The apparent effect is that some part of the sky introduces in the road. Also in foggy scenes, the border strength is reduced in the upper part of the image. These two sources of information were used to make the system more robust. The final purpose of this system was to develop an automatic vision-based diagnostic system for warning ADAS of possible wrong working conditions.

E. Zhang Chaofu, MA Li-ni, Jing Lu-na, " Mixed Frequency domain and spatial of enhancement algorithm for infrared image", 2012 [5] proposed a hybrid technique to enhance the image. It makes use of the Gauss filter processing to enhance image details in the frequency domain and smooth the contours of the image by the top-hat and bot-hat transforms in spatial domain. To enhance the infrared image, this algorithm did not enhanced only the details of the image, but the outline of the image had also been smooth.

F. A. Poljicak, L. Mandic, M. Strgar Kurecic ,"Improvement of the Watermark Detector Performance Using Image Enhancement Filters,"2012[6] considered the influence of some image processing techniques on the watermark detection rate. Watermarking methods are still very sensitive to complex degradation attacks such are JPEG compression, or printscan process, so the detection rate of a watermark method decreases considerably after such attacks on a watermarked image. To improve the detection rate they reduced the degradation of the image by using unsharp, Laplacian or deconvolution filter. For the experiment dataset of 1000 images were watermarked and then compressed or printed and scanned. Degraded images were enhanced using unsharp, Laplacian and blind deconvolution filter. The watermark detection rate before and after enhancement was measured and compared.

G. Seung-Won Jung, Jae-Yun Jeong, and Sung-Jea Ko ,“ Sharpness Enhancement of Stereo Images Using Binocular Just-Noticeable Difference,"2012 [7] proposed a new sharpness enhancement algorithm for stereo images.. They introduced a novel application of the BJND model for the sharpness enhancement of stereo images. An efficient soliution for reducing the overenhancement problem in the sharpness enhancement of stereo images was proposed. The solution was found within an optimization framework with additional constraint terms to suppress the unnecessary increase in luminance values. In addition, the reliability of the BJND model was taken into account by estimating the accuracy of stereo matching. 
H. Hong Zhang, Qian Zhao, Lu Li, Yue-cheng Li, Yu-hu You "“ Muti-scale Image Enhancement Based on Properties of Human Visual System,"2011[8] utilized the LIP(logarithmic image processing) model and considered the characteristics of the human visual system (HVS) to propose a new multi-scale enhancement algorithm. Then a new measure of enhancement based on JND model (Just Noticeable Difference, JND) of human visual system was proposed and used as a tool for evaluating the performance of the enhancement technique.

I. Rajib Kumar Jha, Rajlaxmi Chouhan, P. K. Biswas, “ Noise-induced Contrast Enhancement of Dark Images using Non-dynamic Stochastic Resonance," 2012 [9] proposed a nonlinear non-dynamic stochastic resonance-based technique for enhancement of dark and low contrast images. A low contrast image was treated as a subthreshold signal and noise-enhanced signal processing was applied to improve its contrast. The proposed technique uniquely utilized the addition of external noise to neutralize the effect of internal noise (due to insufficient illumination) of a low contrast image. Random noise was added repeatedly to an image and was successively hard-thresholded followed by overall averaging. By varying the noise intensities, noise induced resonance was obtained at a particular optimum noise intensity. Performance of the proposed technique had been investigated for four types of noise distributions - gaussian, uniform, poisson and gamma. Quantitative evaluation of their performances had been done in terms of contrast enhancement factor, color enhancement and perceptual quality measure.

J. Khairunnisa Hasikin, Nor Ashidi Mat Isa, "Enhancement of the low contrast image using fuzzy set theory," 2012[10] proposed a fuzzy grayscale enhancement technique for low contrast image. This technique was proposed by maximizing fuzzy measures contained in the image. The membership function was then modified to enhance the image by using power-law transformation and saturation operator.

K. Mussarat Yasmin, Muhammad Sharif, Saleha Masood, Mudassar Raza and Sajjad Mohsin ," Brain Image Enhancement - A Survey,"2011 [11] The basic purpose of enhancement operation is to analyze the brain images precisely in order to effectively diagnose and examine the diseases and problems. Brain imaging provides a way to investigate and determine brain related diseases in an efficient and effective manner. The basic objective of this study was to evaluate and discuss different techniques and approaches proposed in order to handle different brain imaging types. The paper provided a short overview of different methods presented in the prospect of brain image enhancement.

L. Xiaoying Fang, Jingao Liu, Wenquan Gu, Yiwen Tang ,“ A Method to Improve the Image Enhancement Result based on Image Fusion,"2011 [12] proposed a method to improve the enhancement result with image fusion method with evaluation on sharpness. Several different evaluation methods and fusion policies were discussed and compared.

\section{Comparison Of Different Techniques:}

Comparison of observations given in all references is discussed here.

TABLE1. Comparative Analysis Of Various Techniques

\begin{tabular}{|c|c|c|c|c|c|}
\hline $\begin{array}{l}\text { Sr } \\
\text { no. }\end{array}$ & $\begin{array}{l}\text { Enhancement } \\
\text { Technique/ } \\
\text { Algorithm }\end{array}$ & Domain & $\begin{array}{l}\text { Measuring } \\
\text { Parameter } \\
\text { s }\end{array}$ & $\begin{array}{l}\text { Application } \quad \text { Area/ } \\
\text { Advantages }\end{array}$ & Limitations \\
\hline 1 & Content Aware & Spatial & $\begin{array}{l}\text { HE } \\
\text { Int. Pair } \\
\text { LRM } \\
\text { ORMIT }\end{array}$ & $\begin{array}{l}\text { Enhance the } \\
\text { appearance of: human } \\
\text { faces, blue skies with or } \\
\text { without clouds without } \\
\text { introducing artifacts. }\end{array}$ & $\begin{array}{l}\text { Unable to recover } \\
\text { information from the } \\
\text { shadowed or dark areas of } \\
\text { images that had near- } \\
\text { black intensities. }\end{array}$ \\
\hline 2 & $\begin{array}{l}\text { Using HSV } \\
\text { color space }\end{array}$ & $\begin{array}{l}\text { Frequenc } \\
\mathrm{y}\end{array}$ & $\begin{array}{l}\text { DV-BV, } \\
\text { Statistical } \\
\text { characterist } \\
\text {-ics }\end{array}$ & $\begin{array}{l}\text { Image processing : } \\
\text { Skin detection, } \\
\text { Computer Graphics }\end{array}$ & $\begin{array}{ll}\text { Lighting } & \text { Conditions } \\
\text { required. } & \end{array}$ \\
\hline 3 & Retinex & $\begin{array}{l}\text { Frequenc } \\
\mathrm{y}\end{array}$ & --- & $\begin{array}{lr}\text { Achives } & \text { color } \\
\text { constancy, } & \\
\text { It does not destroy that } \\
\text { parts of image } \\
\text { do which } \\
\text { do not } & \text { need } \\
\end{array}$ & $\begin{array}{l}\text { Sometimes noise is } \\
\text { enhanced leading to high } \\
\text { entropy. }\end{array}$ \\
\hline
\end{tabular}




\begin{tabular}{|c|c|c|c|c|c|}
\hline & & & & enhancement. & \\
\hline 4 & $\begin{array}{l}\text { Sobel based- } \\
\text { foggy detector }\end{array}$ & Spatial & $\begin{array}{l}\text { Visibility } \\
\text { distance } \\
\text { limits, } \\
\text { Sobel } \\
\text { statistics }\end{array}$ & $\begin{array}{lr}\text { Advanced } & \text { Driver } \\
\text { Assistance } & \text { Systems } \\
\text { (ADAS) } & \end{array}$ & $\begin{array}{l}\text { High edge density, } \\
\text { algorithm classify the } \\
\text { sequence as not foggy } \\
\text { level. }\end{array}$ \\
\hline 5 & $\begin{array}{l}\text { A hybrid } \\
\text { approach }\end{array}$ & $\begin{array}{l}\text { Spatial, } \\
\text { Frequenc } \\
\text { y }\end{array}$ & $\begin{array}{l}\text { Information } \\
\text { Entropy } \\
\text { value, } \\
\text { variance } \\
\end{array}$ & $\begin{array}{l}\text { Details of infrared } \\
\text { image is enhanced and } \\
\text { outline is also } \\
\text { smoothen. }\end{array}$ & --- \\
\hline 6 & $\begin{array}{l}\text { Unsharp, } \\
\text { Laplacian or } \\
\text { Deconvolution } \\
\text { filter. }\end{array}$ & $\begin{array}{l}\text { Spatial, } \\
\text { Frequenc } \\
\text { y }\end{array}$ & --- & $\begin{array}{l}\text { Print-Scan } \\
\text { process, } \\
\text { JPEG Compression }\end{array}$ & $\begin{array}{l}\text { Deconvolution filter is } \\
\text { the slowest of all, } \\
\text { Can't determine attacks } \\
\text { like median filtering, } \\
\text { noise. }\end{array}$ \\
\hline 7 & $\begin{array}{l}\text { Binocular Just- } \\
\text { Noticeable } \\
\text { Difference }\end{array}$ & $\begin{array}{l}\text { Frequenc } \\
\mathrm{y}\end{array}$ & $\begin{array}{l}\text { W in (14) } \\
\text { and } \mathrm{c} 1 \text { and } \\
\mathrm{c} 2 \text { in }(15) \text {. }\end{array}$ & $\begin{array}{l}\text { Sharpness enhancement } \\
\text { of stereo images }\end{array}$ & $\begin{array}{l}\text { Not properly applicable } \\
\text { on color and contrast } \\
\text { enhancements. }\end{array}$ \\
\hline 8 & $\begin{array}{l}\text { Combination of } \\
\text { LIP model and } \\
\text { HSV }\end{array}$ & $\begin{array}{l}\text { Frequenc } \\
\mathrm{y}\end{array}$ & $\begin{array}{l}\text { MSE, } \\
\text { PNSR, } \\
\text { VDD }\end{array}$ & $\begin{array}{l}\text { Used for Contrast } \\
\text { Enhancement }\end{array}$ & $\begin{array}{l}\text { Salt and pepper noise was } \\
\text { not removed, can't be } \\
\text { used for enhancing color } \\
\text { images }\end{array}$ \\
\hline 9 & $\begin{array}{l}\text { A nonlinear } \\
\text { non-dynamic } \\
\text { stochastic } \\
\text { resonance-based }\end{array}$ & Spatial & $\begin{array}{l}\text { F, } \\
\text { PQM, } \\
\text { CEF }\end{array}$ & $\begin{array}{l}\text { Has better } \\
\text { Performance than } \\
\text { existing spatial domain } \\
\text { techniques. }\end{array}$ & $\begin{array}{l}\text { Utilizes addition of } \\
\text { external noise. }\end{array}$ \\
\hline 10 & $\begin{array}{l}\text { Fuzzy grayscale } \\
\text { enhancement }\end{array}$ & Fuzzy & $\begin{array}{l}\text { Processing } \\
\text { Time, t (s) } \\
\text { IOF, } \\
\text { PSNR } \\
\text { (dB), C }\end{array}$ & $\begin{array}{l}\text { Does not enhance } \\
\text { existing noise in the } \\
\text { image, } \\
\text { Requires Minimum } \\
\text { processing Time }\end{array}$ & $\begin{array}{l}\text { Enhances low contrast } \\
\text { images only. }\end{array}$ \\
\hline 11 & $\begin{array}{l}\text { Image } \\
\text { Processing } \\
\text { Techniques like } \\
\text { contrast } \\
\text { stretching, noise } \\
\text { removal etc. }\end{array}$ & $\begin{array}{l}\text { Spatial, } \\
\text { Frequenc } \\
\text { y }\end{array}$ & --- & $\begin{array}{ll}\text { De-noising } & \text { or } \\
\text { enhancement } & \text { of } \\
\text { medical images. } & \end{array}$ & $\begin{array}{lrr}\text { Involves lot } & \text { of } \\
\text { calculations, } & \\
\text { Not practical for } & \text { 3D } \\
\text { medical } & \text { image } \\
\text { enhancement } & & \end{array}$ \\
\hline 12 & Image Fusion & $\begin{array}{l}\text { Frequenc } \\
\mathrm{y}\end{array}$ & $\begin{array}{l}\text { STD, } \\
\text { Contrast, } \\
\text { Average } \\
\text { gradient }\end{array}$ & $\begin{array}{l}\text { Enhances all regions of } \\
\text { the image }\end{array}$ & $\begin{array}{l}\text { Evaluates } \\
\text { statistical } \\
\text { sharpness. }\end{array}$ \\
\hline
\end{tabular}

\section{Conclusion:}

This paper presents a short description of various image enhancement techniques in order to make familiar with the enhancement of a blurred image, noise removal, setting the brightness, contrast and other degradations in images in image processing. Critical review concludes that Modern techniques Retinex (SSR \& MSR) performs much better than Histogram Equilization, Homomorphic filtering because it is based on the color constancy theory, but it still suffers from color violation and unnatural color rendition problem, as The Wavelet transforms is the very good technique for the image denoising and input images always faces the noise during image processing so in future work there is scope of applying Wavelet transform with Retinex to improve the image enhancement results such as color rendition problem. Content Aware technique was unable to enhance the dark areas of image but image fusion technique overcomes this limitation and enhances all regions of an image. 


\section{References:}

[1] A. R. Rivera, B. Ryu, and O. Chae, "Content-Aware Dark Image Enhancement Through Channel Division" IEEE Transactions On Image Processing, Vol. 21, No. 9, September 2012

[2] D. Ghimire and J. Lee "“ Nonlinear Transfer Function-Based Local Approach for Color Image Enhancement,” IEEE Transactions on Consumer Electronics, Vol. 57, No. 2, May 2011.

[3] S. Parthasarathy, P. Sankaran,“ Fusion Based Multi Scale RETINEX with Color Restoration for Image Enhancement," 2012 International Conference on Computer Communication and Informatics (ICCCI -2012), Jan. 10 - 12, 2012, Coimbatore, India

[4] S. Bronte, L. M. Bergasa, P. F. Alcantarilla, "Fog Detection System Based on Computer Vision Techniques".

[5] Z. Chaofu, M. Li-ni, J. Lu-na "“ Mixed Frequency domain and spatial of enhancement algorithm for infrared image”, 20129 th International Conference on Fuzzy Systems and Knowledge Discovery (FSKD 2012).

[6] A. Poljicak, L. Mandic, M. Strgar Kurecic ," Improvement of the Watermark Detector Performance Using Image Enhancement Filters,” IWSSIP 2012,11-13 April 2012,Vienna, Austria.

[7] S. W. Jung, J.Y. Jeong, and S.J. K " Sharpness Enhancement of Stereo Images Using Binocular Just-Noticeable Difference," IEEE Transactions On Image Processing, Vol. 21, No. 3, March 2012

[8] H. Zhang, Q. Zhao, Lu Li, Y.c. Li, Y.h. You , "Muti-scale Image Enhancement Based on Properties of Human Visual System,” 2011 4th International Congress on Image and Signal Processing.

[9] R. K. Jha, R. Chouhan, P. K. Biswas " Noise-induced Contrast Enhancement of Dark Images using Non-dynamic Stochastic Resonance," 978-1-4673-0816-8/12S @2012 IEEE.

[10] K. Hasikin, N. A. Mat Isa " Enhancement of the low contrast image using fuzzy set theory," 2012 14th International Conference on Modelling and Simulation.

[11] X. Fang, J. Liu, W. Gu, Y. Tang ,“ A Method to Improve the Image Enhancement Result based on Image Fusion,” 978-1-61284774-0/11 @2011 IEEE.

[12] M. Yasmin, M. Sharif, S. Masood, M. Raza and S. Mohsin ,“ Brain Image Enhancement - A Survey,” World Applied Sciences Journal 17 (9): 1192-1204, 2012,ISSN 1818-4952@ IDOSI Publications, 2012.

[13] Rafael, C. Gonzalez and R. E. Woods, digital image processing: 2nd edition, Prentice Hall, 2002.

[14] D. Scharstein and R. Szeliski, [Online]. Available: http://vision.middlebury. edu/stereo.

[15] T. F. Coleman and Y. Li, "A reflective Newton method for minimizing a quadratic function subject to bounds on some of the variables," SIAM J. Optim., vol. 6, no. 4, pp. 1040-1058, 1996. 